\title{
Larval feeding capacity and pollination efficiency of the aphidophagous syrphids, Eupeodes frequens (Matsmura) and Episyrphus balteatus (De Geer) (Diptera: Syrphidae) on the cabbage aphid (Brevicoryne brassicae L.) (Homoptera: Aphididae) on mustard crop
}

Paramveer Singh ${ }^{*}$ (D), Meena Thakur, Karishan Chander Sharma, Harish Kumar Sharma and Rohit Kumar Nayak

\begin{abstract}
The present investigation was carried out on in vitro mass multiplication, larval feeding capacity, and pollination efficiency of two aphidophagous syrphids viz., Eupeodes frequens (Matsmura) and Episyrphus balteatus (De Geer) (Diptera: Syrphidae) on cabbage aphid (Brevicoryne brassicae L.) (Homoptera: Aphididae) on mustard crop under mid hill conditions. The results revealed that the incubation, larval, and pupal periods were 3.5, 12.4, and 11.9 days, respectively for $E$. frequens and 3.8, 13.7, and 8.8 days, for E. balteatus. Longevity of male and female was 15.2 and 17.6 days for $E$. frequens and 10.6 and 12.6 days for $E$. balteatus, respectively. When the adults were fed on different diets, adult longevity and fecundity recorded significantly maximum on $10 \%$ honey solution + fresh pollen grains. $E$. frequens consumed an average of 261.7 individuals of cabbage aphids per larva during total larval period, whereas the larva of E. balteatus consumed 393.6 cabbage aphids. The pollination efficiency of hoverflies on Indian mustard (Brassica juncea L.) was studied under caged conditions. It was observed that the plants pollinated by E. balteatus and $E$. frequens showed 55.12 and $52.97 \%$ seed set. Among the different diets, fresh pollen grains $+10 \%$ honey solutions recorded to be the best diet for mass rearing of syrphids.
\end{abstract}

Keywords: Syrphids, Episyrphus balteatus, Eupeodes frequens, Brevicoryne brassicae, pollination efficiency

\section{Background}

Oil seed crops are next to cereals in production of agricultural commodities in India. They occupy a place of prime importance in Indian economy. In India, mustard, Brassica juncea (Linnaeus) (family Cruciferae) is an important oil seed crop grown in Rabi season. In India, the total cultivated area is 5799.08 ha with an annual

\footnotetext{
* Correspondence: paramdhonsi93@gmail.com

Department of Entomology, Dr Y.S. Parmar University of Horticulture and Forestry, Nauni, Solan, Himachal Pradesh 173230, India
}

production of 6282.40 MT during 2016-17 (Rathore et al. 2018). It is the second most important oilseed crop of the world as well as India after groundnut. In India, Rajasthan is the largest producer of rapeseed and mustard followed by Uttar Pradesh, Haryana, West Bengal, and Gujarat (Rathore et al. 2018). The cabbage aphid (Brevicoryne brassicae L.) (Aphididae, Homoptera) is the most destructive pest of Brassicaceae plants. Its attack, results in severe distortion of leaves, and heavy losses to crops by forming large colonies on leaves, stems, and 
inflorescence resulting in slow growth of the plant causing 9-77 and $11 \%$ loss in total seed yield and oil content, respectively (Khan et al. 2015).

The conventional pest control technology for aphid control is primarily based on applications of chemical insecticides, and complete eradication of the pest requires frequent application of insecticides. Indiscriminate use of pesticides leads to destruction of natural enemies and pollinators, toxic residues in crop plants, pesticide resistance, and environmental pollution. Therefore, to overcome these problems, ecofriendly practices, mainly use of bio control agents are encouraged. Among the aphidophagous insects, larvae of the syrphid flies (Syrphidae: Diptera) are an important natural enemy. Syrphid flies are known by various names such as "Hoverflies," "Sunflies," "Flowerflies," or "droneflies." These belong to family Syrphidae which includes subfamilies viz. Microdontinae, Eristalinae, and Syrphidae. Among 3 subfamilies, only hoverflies of subfamily Syrphinae are aphid predators, 2 are saprophagous, and phytophagous in nature. They play an important role in the suppression of natural population of many economically important species of aphids like Lipaphis erysimi, B. brassicae (Linnaeus), and Aphis craccivora (Koch). Syrphids lay eggs at the beginning of aphid population buildup and they are considered to be effective biological agents for the management of the early aphid population (Awadallah et al. 1980). Adult syrphid flies are strong fliers and reported as efficient pollinators of many agricultural as well as of non-agricultural crops (Sutherland et al. 1999). Among the various aphidophagous syrphid flies, Episyrphus balteatus (De Geer) and Eupeodes frequens (Matsmura) are the most commonly and predominant species worldwide in agriculture ecosystem (Sadeghi 2008). In mid hill region of Himachal Pradesh, E. frequens has been found to predate upon B. brassicae infesting cauliflower. Larvae of $E$. balteatus are predators of more than 100 aphid species worldwide (Sadeghi and Gilbert 2000). B. juncea is a self-incompatible crop due to which flowers cannot utilize their own pollen and needs pollinators like different insect species to transfer the pollen from male to female flowers (Roy et al. 2014). Hence, insect pollinators are very important source of pollination for producing seeds and to get optimum yield (Devi et al. 2017). Adults of syrphid species help in cross-pollination of oil seed crops. The plants pollinated by E. balteatus and Eupeodes sp. produce significantly high number of seeds per siliqua and yield per plot (Jauker and Wolters 2008). Thus, the adults of E. balteatus and $E$. frequens have strong ability to forage for aphid colonies, pollens, and nectar. They are capable of crushing the pollen grains for feed and have proved themselves as efficient pollinators. With the view of their importance as aphid predator and pollinator as well, this research was carried out for studying their biology, predation efficiency, possibility of in vitro rearing, and pollination efficiency.

\section{Materials and methods}

Stock culture of $E$. frequens and $E$. balteatus was maintained at $25 \pm 2{ }^{\circ} \mathrm{C}$ and $50 \pm 5 \%$ relative humidity in Vegetable Entomology Laboratory, Department of Entomology, Dr Y.S. Parmar University of Horticulture and Forestry, Nauni, Solan (HP). One pair of adult flies was released in each glass chimney $(10 \times 14.5 \mathrm{~cm})$, and a cotton swab soaked with $10 \%$ sucrose solution was provided as feeding material. Aphid infested mustard floral buds dipped in water in small vials were also kept in the same chimney for providing fresh pollen source and for enhancing the egg laying by the female syrphid flies. The top of the glass chimney was covered by muslin cloth and tied with rubber band.

Every day cotton swab was changed and new cotton swab soaked with $10 \%$ sugar solution was kept in the chimney. The floral buds were also replaced by new aphid-infested ones, when the older ones dried. Eggs from the stock culture were collected from floral buds, pods, and branches of potted mustard floral buds gently by a camel hair brush and kept in homeopathic vials (1.5 $\times 5 \mathrm{~cm}$ ); only one egg was kept in each vial and plugged with cotton.

The newly emerged syrphid larvae were fed on a counted number of cabbage aphids, and different instars are as follows:

- First instar syrphid larvae were fed on of 1 st and 2nd instar nymphs of aphids (50 aphids were offered to a single larva daily).

- Second instar syrphid larvae were fed on3rd instar nymphs of aphids (100 aphids were offered to each larva daily).

- Third instar syrphid larvae were fed on 4th instar nymphs of aphids and winged adults (200 aphids were offered to each larva daily).

- Everyday unfed aphids were removed and fresh ones were provided to the syrphid larvae till pupation. To evaluate the effect of different diets on longevity and fecundity per female, one pair of newly emerged syrphid adult of each species was placed in different glass chimneys and fed on different diets. The whole set of experiment was held with 3 treatments and 7 replications and analyzed statistically (CRD). The treatments were as follows:

T1 10\% sugar solution + fresh mustard pollen grains T2 10\% honey solution + fresh mustard pollen grains T3 10\% glucose + fresh mustard pollen grains

To study the effect of diets on longevity and fecundity, experiment was replicated 7 times. 


\section{Biology of syrphids}

The biology of E. frequens and E. balteatus was studied under laboratory conditions at $25 \pm 2{ }^{\circ} \mathrm{C}$ and $50 \pm 5 \%$ $\mathrm{RH}$.

Biology parameters studied were as follows:

- Incubation period

- Duration of larval stage (the 3instars)

- Duration of pupal period and adult longevity

\section{Feeding capacity of syrphid larvae}

Daily total number of aphids consumed by each syrphid larva was recorded till pupation to determine the feeding capacity of syrphid larva (10 replications).

\section{Effect of pollination on yield parameters in mustard}

To study the impact of different modes of pollination on different yield attributes of mustard, percent seed set, number of seeds/siliqua, and weight of 1000 seeds, 6 different treatments were applied. In open pollination, the crop was left open and bloom was exposed to all the pollinators; in hand pollination, before opening, the flower buds were covered with butter paper bags. After $24 \mathrm{~h}$ of anthesis, pollens were applied over the stigma with the help of camel hair brush. Only counted numbers of pollinated buds were retained and extra buds were removed and recovered again with butter paper bag. After shading of patels when pods started developing, bags were removed. Four cages of nylon net each measuring $\left(1 \times 1 \times 1.5 \mathrm{~m}^{3}\right)$ were erected over different plots of mustard according to different treatments (each treatment (including control) was replicated 4 times) before initiation of bloom. For syrphid pollination, both $E$. frequens and E. balteatus (10 syrphids) were released in cages at $10 \%$ bloom. The cages of 4 th treatment were without pollinators (control). The observation on various yield parameters like percent seed set, numbers of seeds per siliqua, and 1000 seed weight were recorded with respect to the impact of different modes of pollination on mustard crop.

\section{Statistical analysis}

Data recorded on various parameters was analyzed statistically using suitable transformation (where needed) at $5 \%$ level of significance using Microsoft excel and OPSTAT and SPSS.

\section{Results and discussion}

Duration of developmental stages and predatory potential of Eupeodes frequens and Episyrphus balteatus on Brevicoryne brassicae

Durations of different developmental stages of $E$. frequens and E. balteatus are presented in Table 1. The average incubation period of $E$. frequens and E. balteatus was $3.5 \pm 0.22$ and $3.8 \pm 0.16$ days, respectively. The duration of the 1st, 2nd, and 3rd larval instars lasted $4.2 \pm$ $0.20,3.4 \pm 0.16$, and $4.8 \pm 0.20$ days for $E$. frequens and $4.8 \pm 0.25,3.3 \pm 0.21$ and $5.6 \pm 0.27$ days for $E$. balteatus with a total larval period of $12.4 \pm 0.27$ and $13.7 \pm 0.45$ days, respectively. The mean pupal period was $11.9 \pm$ 0.48 days for $E$. frequens and $8.8 \pm 0.36$ days for $E$. balteatus. The average longevity of male and female of $E$. frequens was recorded as $15.2 \pm 0.74$ and $17.6 \pm 0.68$ days, respectively. Adult longevity ranged 16-19 days in females and 13-17 days in males. Female of E. frequens lived longer than the males. The longevity of males and females of E. balteatus was recorded as $10.6 \pm 0.51$ and $12.6 \pm 0.51$, respectively. In E. balteatus, also females lived longer than males. The longevity ranged 11-14 days for females and 9-12 days for males for E. balteatus

The predatory capacity of $E$. frequens and $E$. balteatus different larval instars on the cabbage aphid was also studied. The 1st instar larva of E. frequens and E. balteatus consumed $34.4 \pm 2.38$ (27-46) and $39.6 \pm 1.91$ aphids, respectively. The 2nd and 3rd instar larvae of $E$. frequens consumed $67.2 \pm 3.08$ (52-85) and $184.4 \pm 6.51$ aphids (164-221), respectively. Correspondent consumptions of E. balteatus were $114.8 \pm 1.66(103-124)$ and $237.3 \pm 3.04$ aphids (220-251). As an average, a single larva of $E$. frequens consumed $261.7 \pm 4.37$ aphids (251-292), while $E$. balteatus single larva consumed $393.6 \pm 3.44$ aphids (range 375-407 aphids) during its total larval period.

The results of the present findings are more or less in agreement with those of Verma et al. (2005) who studied the biology and predatory potential of $E$. frequens on black bean aphid (Aphis fabae) under laboratory conditions and reported that the incubation period of this species was $4-5$ days, while the duration of the 1 st, 2 nd, and 3rd instars was 4-6, 3-4, and 5-6 days, respectively. The total larval period varied from 13 to 15 days and the pupal period was 9-12 days. The longevity of male varied from 4 to 12 days, while in female, it varied from 8 to 10 days. They reported the predatory capacity of $E$. frequens on $A$. fabae during different larval instars as 17-31, 33-36, and 176-329 aphids/larva for 1st, 2nd, and 3rd instars, respectively. It consumed 257-415 aphids during its total larval period. In the study of Hopper et al. (2011), up to 507 3rd instar lettuce aphids (Nasonovia ribisnigri) were consumed by Eupeodes fumipennis.

In a study done by Jalilian et al. (2016), they reported different biological parameters of Eupeodes corollae on Aphis pomi which support our present study. They reported the mean duration of 1st, 2nd, and 3rd instar larvae was $3.40,4.60$, and 4.90 days, respectively.

The results of the present findings are in agreement with the finding of Jalilian (2015b) who studied the biology and feeding potential of larvae of $E$. balteatus on 
Table 1 Duration of different developmental stages and predatory potential of Eupeodes frequens

\begin{tabular}{|c|c|c|c|c|c|}
\hline \multirow[t]{2}{*}{ Stage } & & \multicolumn{2}{|l|}{ Eupeodes frequens } & \multicolumn{2}{|l|}{ Episyrphus balteatus } \\
\hline & & $\begin{array}{l}\text { Mean duration } \\
\text { (days } \pm \mathrm{SE} \text { ) }\end{array}$ & $\begin{array}{l}\text { Mean aphid consumption } \\
\pm \text { SE }\end{array}$ & $\begin{array}{l}\text { Mean duration } \\
\text { (days } \pm \mathrm{SE} \text { ) }\end{array}$ & $\begin{array}{l}\text { Mean aphid consumption } \\
\pm \text { SE }\end{array}$ \\
\hline Egg & & $3.5 \pm 0.22^{* *}(3-5)^{*}$ & - & $3.8 \pm 0.16(3-5)^{*}$ & - \\
\hline \multirow[t]{3}{*}{ Larva } & 1st instar & $4.2 \pm 0.20(3-5)$ & $34.4 \pm 2.38(27-46)^{*}$ & $4.8 \pm 0.25(4-6)$ & $39.6 \pm 1.91(29-47)^{*}$ \\
\hline & 2nd instar & $3.4 \pm 0.16(3-4)$ & $67.2 \pm 3.08(52-85)$ & $3.3 \pm 0.21(3-4)$ & $114.8 \pm 1.66(103-124)$ \\
\hline & 3rd instar & $4.8 \pm 0.20(4-6)$ & $184.4 \pm 6.51(164-221)$ & $5.6 \pm 0.27(4-7)$ & $237.0 \pm 3.04(220-251)$ \\
\hline Total & & $12.4 \pm 0.27(11-14)$ & $261.7 \pm 4.37(251-292)$ & $13.7 \pm 0.45(12-16)$ & $393.6 \pm 3.44(375-407)$ \\
\hline$F$ values & & - & 152.99 & - & 163.42 \\
\hline$P$ values & & - & $<0.001$ & - & $<0.0001$ \\
\hline Pupal period & & $11.9 \pm 0.48(9-13)$ & & $8.8 \pm 0.36(8-11)$ & - \\
\hline \multirow[t]{3}{*}{ Adult longevity } & Male & $15.2 \pm 0.74(13-17)$ & & $10.6 \pm 0.51(9-12)$ & - \\
\hline & Female & $17.6 \pm 0.68(16-19)$ & & $12.6 \pm 0.51(11-14)$ & - \\
\hline & $t$ values & 0.0003 & & 0.0009 & \\
\hline
\end{tabular}

*Values in parentheses are the range values

**Mean \pm SE of 10 individuals

$t$ test for adult longevity (male-female)

green apple aphid Aphis. pomi at $25 \pm 2{ }^{\circ} \mathrm{C}$ and $50-60 \%$ $\mathrm{RH}$ at Kermanshah, Iran. The average incubation period was 4 days, while the total larval period varied from 11 to 12 days comprising 3, 3.40, and 4.90 for the1st, 2nd, and 3rd instars, respectively. The pupal period varied from 7 to 8 days and the adult longevity varied from 9 to 10 days.

\section{Aphid consumption at different larval instars}

It was observed that number of consumed aphids increased with each successive larval instar and start decreasing when the larva full fed and ready to pupate. Figure 1 shows the trend of daily aphid consumption by both species; it gradually increased day after day reaching the peak of $184 \pm 6.51$ and $237 \pm 3.04$ aphids by 3rd instar larva of $E$. balteatus and $E$. frequens, respectively and then started to decrease until larvae stopped eating. From the present investigation, it was observed that larva of syrphids consumed very less number of aphids just after emergence and just before pupation (Fig. 1).

The size and predation rate on cabbage aphid (B. brassicae) by each larva gradually increased with each successive instar; it attained largest size in 3rd instar. Predation on cabbage aphid at 3rd instar increased to the maximum with mean aphid consumption of $393.6 \pm$ 3.44 and $261.7 \pm 4.37$ aphids for $E$. balteatus and $E$.

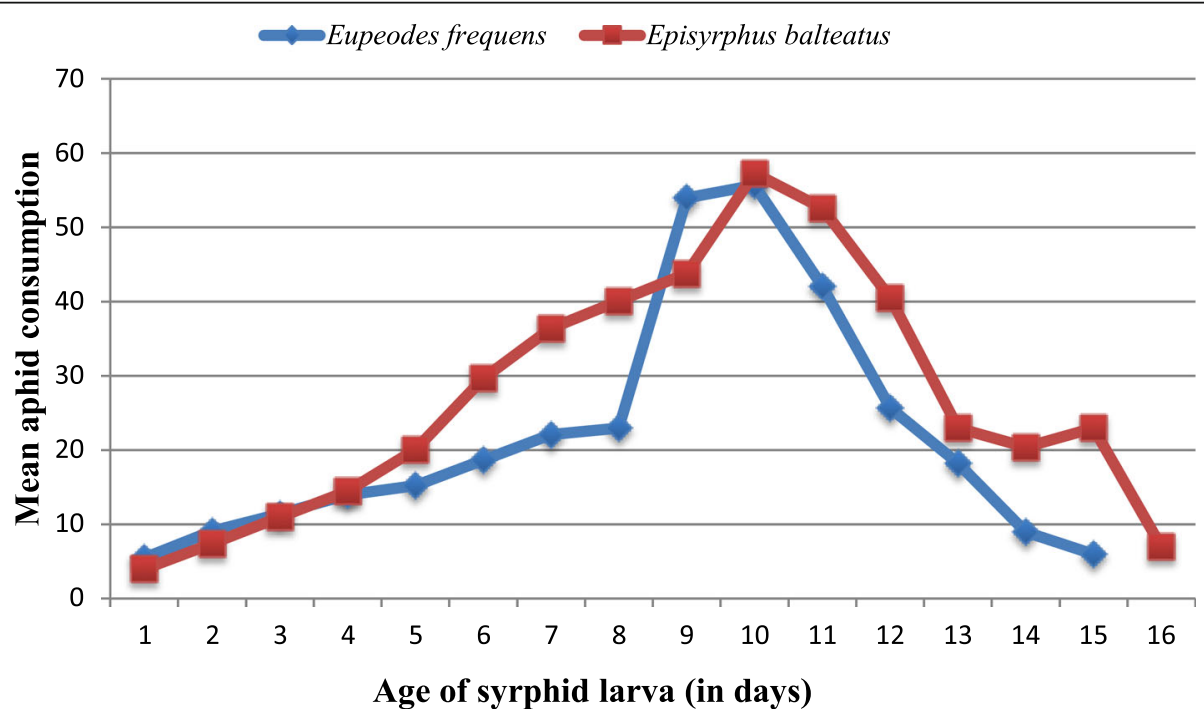

Fig. 1 Trend of daily consumption by Eupeodes frequens and Episyrphus balteatus on Brevicoryne brassicae till pupation (signs indicate mean values of 10 replications) 
frequens, respectively. Since the body size of the syrphid larva increased gradually at different instars and being the maximum in the 3rd instar, thus it may be possible that this instar could consume maximum aphids. Singh and Singh (2013) reported from their study that last instar of syrphid larvae consumed maximum number of 167 aphids of Lipaphis erysimi which were highest than rest of two larval instars.

\section{Longevity of syrphids' adults on different diets}

Longevity of $E$. frequens on different diets revealed that the longevity of males and females varied from 15.219.6 to $17.6-22.8$ days, respectively (Table 2 ). The effect of feeding of males and females on different diets was non-significant, though maximum longevity was observed for female $(22.8 \pm 0.74$ days $)$ at $10 \%$ honey solution + fresh mustard pollen grains (T2), whereas the lowest one $(13.14 \pm 1.05$ days) was observed for male at $10 \%$ glucose solution + fresh mustard pollen grains (T3). Irrespective to the sex, maximum longevity was observed on $10 \%$ honey solution + fresh mustard pollen grains (T2) followed by (T1) 10\% sucrose solution + fresh mustard pollen grains, whereas statistically, minimum longevity was observed on (T3) $10 \%$ glucose solution + fresh mustard pollen grains for both sexes of $13.14 \pm$ 1.05 and $15.43 \pm 1.24$ days for male and female, respectively.

The longevity of males and females of E. balteatus (Table 3) varied from $9.86-13.57$ days to $11.57-15.14$ days, respectively. Maximum longevity $(15.14 \pm 0.48$ days) was observed for females at $10 \%$ honey solution + fresh mustard pollen grains (T2), whereas the minimum (9.86 \pm 0.79 days) was observed for male at $10 \%$ glucose solution + fresh mustard pollen grains (T3). Significantly, minimum longevity was observed on diet (T3) for both sexes and was maximum at $\mathrm{T} 2$. These results are more or less similar to the findings of Iwai et al. (2007); these results agree with from the findings of Hong and Hung (2010) who reported that the longevity of $E$. balteatus increased when they were fed on $10 \%$ honey solution along with pollen grains. As compared to the present study, Jalilian (2015a) reviewed that longevity of other syrphid species viz. Scaeva pyrastri and Betasyrphus srearius was reported as 8.0 days (female) and 8.5 days (male) and 23.0 days (female) and 15.8 days (male), respectively on $10 \%$ honey solution and fresh mustard pollen grains. Further, in their study, $10 \%$ honey solution alone (longevity for both the species varied from 14.7 to 19.0 days) was found to be better than other combinations of $10 \%$ honey solution with protinex, dry pollens, and fresh pollens. Jalilian (2015b) also reported that $10 \%$ honey solution increased the survival of E. balteatus (9.50 days) as compared to nonfeeding situation ( 3.5 days).

\section{Fecundity of syrphids on different diets}

The total egg laying capacity of E. frequens and E. balteatus on different diets was studied under laboratory conditions. The data presented in Table 4 reveals that one female of $E$. frequens laid an average of $37.86 \pm 2.3$, $47.86 \pm 1.2$, and $32.57 \pm 1.4$ eggs on different diets viz. $\mathrm{T} 1, \mathrm{~T} 2$, and T3, respectively during its life span. When the female was fed on $10 \%$ honey solution + fresh pollen grains (T2), a single female of $E$. frequens and $E$. balteatus laid an average of $47.86 \pm 1.2$ eggs and $41.14 \pm 2.5$ eggs/female, respectively. A single female of $E$. frequens laid an average of $32.57 \pm 1.4$ eggs and of $E$. balteatus laid an average of $28.14 \pm 1.8$ eggs, when fed on $10 \%$ glucose solution + fresh pollens (T3). Among the diets statistically, the fecundity of both aphidophagous species of syrphid was maximum, when females fed on $10 \%$ honey solution + fresh mustard pollen grains (T2), followed by at $10 \%$ sucrose solution + fresh mustard pollen grains (T1), whereas the minimum fecundity was observed at $10 \%$ glucose solution + fresh mustard pollen grains (T3). Irrespective of diets, among both the species, E. frequens found to be more egg laying capacity per female than E. balteatus.

The overall studies thus revealed that egg laying capacity of both the species increased when the females were fed on $10 \%$ honey solution and fresh pollen grains. These findings agree with Manpoong et al. (2016) who reported that female of $E$. viridaureus laid on an average

Table 2 Longevity of Eupeodes frequens on different diets

\begin{tabular}{lll}
\hline Diets & \multicolumn{2}{l}{ Duration (days) mean \pm SE } \\
\cline { 2 - 3 } & Male & $17.6 \pm 0.68^{\mathrm{a}}$ \\
\hline (T1) $10 \%$ sucrose solution + fresh mustard pollens & $15.2 \pm 0.74^{\mathrm{b}}$ & $22.8 \pm 0.74^{\mathrm{b}}$ \\
(T2) $10 \%$ honey solution + fresh mustard pollens & $19.6 \pm 0.81^{\mathrm{c}}$ & $15.43 \pm 1.24^{\mathrm{a}}$ \\
(T3) $10 \%$ glucose solution + fresh mustard pollens & $13.14 \pm 1.05^{\mathrm{a}}$ & 35.68 \\
$F_{\text {(df 2-18) }}$ values & 28.12 & $<0.0001$ \\
$P$ values & $<0.0001$ & \\
\hline
\end{tabular}

Means of seven replications

Mean values with different letters are significantly different

$\mathrm{CD}_{0.05}$ at $5 \%$ level of significance, diets $=1.29$, sex $=1.06$, diets $\times$ sex $=\mathrm{NA}$ 
Table 3 Longevity of Episyrphus balteatus on different diets

\begin{tabular}{lll}
\hline Diets & Duration (days) & Female \\
\cline { 2 - 3 } & Male & $13.14 \pm 0.60^{* \mathrm{~b}}$ \\
\hline (T1) 10\% sucrose solution + fresh mustard pollens & $10.57 \pm 0.44^{*^{\mathrm{a}}}$ & $15.14 \pm 0.48^{\mathrm{c}}$ \\
(T2) 10\% honey solution + fresh mustard pollens & $13.57 \pm 0.44^{\mathrm{b}}$ & $11.57 \pm 0.68^{\mathrm{a}}$ \\
(T3) $10 \%$ glucose solution + fresh mustard pollens & $9.86 \pm 0.79^{\mathrm{a}}$ & 12.84 \\
$F_{\mathrm{df}(2-18)}$ values & 16.16 & $<0.0001$ \\
$P$ values & $<0.0001$ & $<$
\end{tabular}

"Mean values of seven replications

Mean values with different letters are significantly different

$\mathrm{CD}_{0.05}$ \{diets $=1.00$, sex $=0.82$, diets $\times$ sex $\left.=N A\right\}$

45.4 eggs and of Betasyrphus isaaci laid an average 31.2 eggs throughout its life span when fed on $50 \%$ honey solution. The observations of the present investigation are supported by the findings of Hong and Hung (2010) who reported that rearing temperature and food type may affect some biological characters, e.g., longevity and egg laying capacity of syrphids. Honey solution and crystalline sugar are reported to promote egg production of E. balteatus.

\section{Impact of different modes of pollination on yield attributes in mustard}

The data presented in Table 5 indicates the impact of different modes of pollination on percent seed set, number of seeds per siliqua, and 1000 seed weight in mustard. The seed set percentage was found to be maximum by hand pollination, i.e., $84.38 \%$ followed by open pollination (79.46\%) and pollination by E. balteatus (55.12\%), which was statistically at par with pollination by $E$. frequens (52.97\%). Minimum (39.83\%) seed set percentage was observed in pollinator exclusion cage (control). The number of seeds per siliqua was observed by the maximum in open pollinated plots, i.e., 19.05 seeds followed by pollination by E. balteatus (16.68 seeds/siliqua) which was significantly the same as $E$. frequens (16.10 seeds/siliqua). Among different modes of pollination, minimum (12.91)

Table 4 Fecundity of Eupeodes frequens and Episyrphus balteatus on different diets

\begin{tabular}{lll}
\hline Diets & $\begin{array}{l}\text { Eupeodes } \\
\text { frequens }\end{array}$ & $\begin{array}{l}\text { Episyrphus } \\
\text { balteatus }\end{array}$ \\
\hline $\begin{array}{l}\text { (T1) 10\% sucrose solution + fresh } \\
\text { mustard pollens }\end{array}$ & $37.86 \pm 2.3^{* b}$ & $33.43^{*} \pm 1.3^{\mathrm{b}}$ \\
$\begin{array}{l}\text { (T2) } 10 \% \text { honey solution + fresh } \\
\text { mustard pollens }\end{array}$ & $47.86 \pm 1.2^{\mathrm{c}}$ & $41.14 \pm 2.5^{\mathrm{c}}$ \\
$\begin{array}{l}\text { (T3) } 10 \% \text { glucose solution + fresh } \\
\text { mustard pollens }\end{array}$ & $32.57 \pm 1.4^{\mathrm{a}}$ & $28.14 \pm 1.8^{\mathrm{a}}$ \\
$F_{\mathrm{df}(2-18)}$ values & 45.35 & 19.55 \\
$P$ values & $<0.0001$ & $<0.0001$ \\
\hline
\end{tabular}

*Mean of seven replications

$\mathrm{CD}_{0.05}$ \{species $=2.20$, diets $\left.=2.70\right\}$ number of seeds per siliqua was observed in pollinator exclusion cages. The weight of 1000 seeds (test weight) was significantly, maximum in open pollinated plots, i.e., 2.39 g, followed by E. balteatus (1.93 g) and E. frequens $(1.87 \mathrm{~g})$. Minimum 1000 seed weight (1.43 g) was observed in pollination exclusion cage (control).

The data illustrated in Fig. 2, revealed the percent increase in seed set, number of seeds/siliqua, and 1000 seed weight by different modes of pollination in comparison to pollinator exclusion cage (control). The percent increase in seed set (70.64\%), number of seeds/ siliqua (17.20\%), and 1000 seed weight $(23.78 \%)$ were recorded in hand pollination over control. The crop pollinated by $E$. frequens and E. balteatus resulted in (19.41 and $22.5 \%$ ) increase in seed set, number of seeds/siliqua (24.70 and 29.20\%), and 1000 seed weight (30.77 and $34.97 \%$ ) increases was recorded over control (pollinator exclusion cage).

The important role of hover flies as pollinator of arable crops under varying environmental conditions was reported (Jauker and Wolter 2008). In the present study, $E$. balteatus and $E$. frequens increased the seed set percentage from $39.03 \%$ (control) to 52.97 and $55.12 \%$, respectively. Jauker and Wolters (2008) reported that hover flies significantly increased the mean number of seeds per pod from 17.75 in control to 22.25 seeds per pod. According to Morandin and Winston (2006), pollinators increased the number of seeds by 1.8 seeds per pod corresponding to a yield gain of oil seed by about $10 \%$.

In the present study, 19.41 to $22.58 \%$ increment in seed set by syrphids was observed, which finds support from the observations of Morandin and Winston (2006), wherein yield gain by 15 to $25 \%$ was observed further resistance on hover flies to fluctuating environment conditions is reported. Obtained findings of effect of syrphids on seed set percentage of mustard were supported by studies on wild flowers Vance et al. (2004).

In the present study, highest seed set percentage $(84.38 \%)$ was observed by using hand pollination followed by open pollination (79.46\%). Goswami and Khan (2014) reported a highest percent pod set of 
Table 5 Impact of different modes of pollination on percent seed set, number of seeds per siliqua, and test weight (1000 seeds) in mustard

\begin{tabular}{llll}
\hline Mode of pollination & Percent seed set & Seeds/siliqua & Test weight (1000 seed) (g) \\
\hline Open pollination & $79.46^{* *}(63.10)^{* \mathrm{~b}}$ & $19.05^{\mathrm{a}}$ & $2.39^{\mathrm{a}}$ \\
Hand pollination & $84.38(66.72)^{\mathrm{a}}$ & $15.13^{\mathrm{c}}$ & $1.77^{\mathrm{b}}$ \\
Syrphid (E. balteatus) & $55.12(47.93)^{\mathrm{c}}$ & $16.68^{\mathrm{b}}$ & $1.93^{\mathrm{b}}$ \\
Syrphid (E. frequens) & $52.97(46.69)^{\mathrm{c}}$ & $16.10^{\mathrm{b}}$ & $1.87^{\mathrm{b}}$ \\
Control (pollinator exclusion) & $39.83(39.10)^{\mathrm{d}}$ & $12.91^{\mathrm{d}}$ & $1.43^{\mathrm{c}}$ \\
F values & 84.41 & 35.61 & 19.58 \\
$P$ values & $<0.00001$ & $<0.0001$ & 0.0001 \\
$C D_{0.05}$ & 2.87 & 1.17 & 0.21 \\
\hline
\end{tabular}

*Values in parentheses are angular transformed mean

**Mean values of 4 replications

Mean values with different letters are significantly different

$83.42 \%$ in open pollination plots of B. juncea followed by bee pollination $(75.41 \%)$ and pollination exclusion (62.80\%). Devi et al. (2017) stated that $81.60 \%$ seed set of mustard crop in open pollination plots and $25.0 \%$ in pollinator exclusion cage of B. juncea than $39.83 \%$ recorded in present investigation. Goswami and Khan (2014) in their study on effect of insect pollination on percent seed set of different varieties of $B$. juncea recorded 66.33 to $96.91 \%$ pod set in open pollination and 53.76 to $93.50 \%$ pod set by bee pollination and 48.41 to $83.78 \%$ pod set in pollinator exclusion cages. Nagpal et al. (2017) also recorded $86.32,78.33$, and $65.87 \%$ pod set of $B$. juncea in open pollination bee pollination and pollinator exclusion cages, respectively. The present results are in accordance with the findings of Hodgkiss et al. (2018) wherein both the hover fly species treatment and hand pollination cages, fruit yields of strawberry per cage were enhanced by more than $90 \%$ when compared to pollinator exclusion cages.

In present investigation, both syrphid species were statistically at par with each other in percent seed set, whereas based on its impact on pollination success, fruit weight, and marketability, Eupeodes latifasciatus was reported to be more effective pollinator of strawberry flower than E. Balteatus Hodgkiss et al. (2018).

Number of seeds per siliqua varied from 12.91 (control) to 19.05 (open pollination). In E. balteatus and $E$. frequens pollinated pots, the seeds per siliqua were 16.68 and 16.10 , respectively which was less than open pollination (19.05 seeds per pod). Nagpal et al. (2017) recorded 14.26 mean numbers of seeds per pod for $B$. juncea for bee pollination, 15.66 for open pollination,

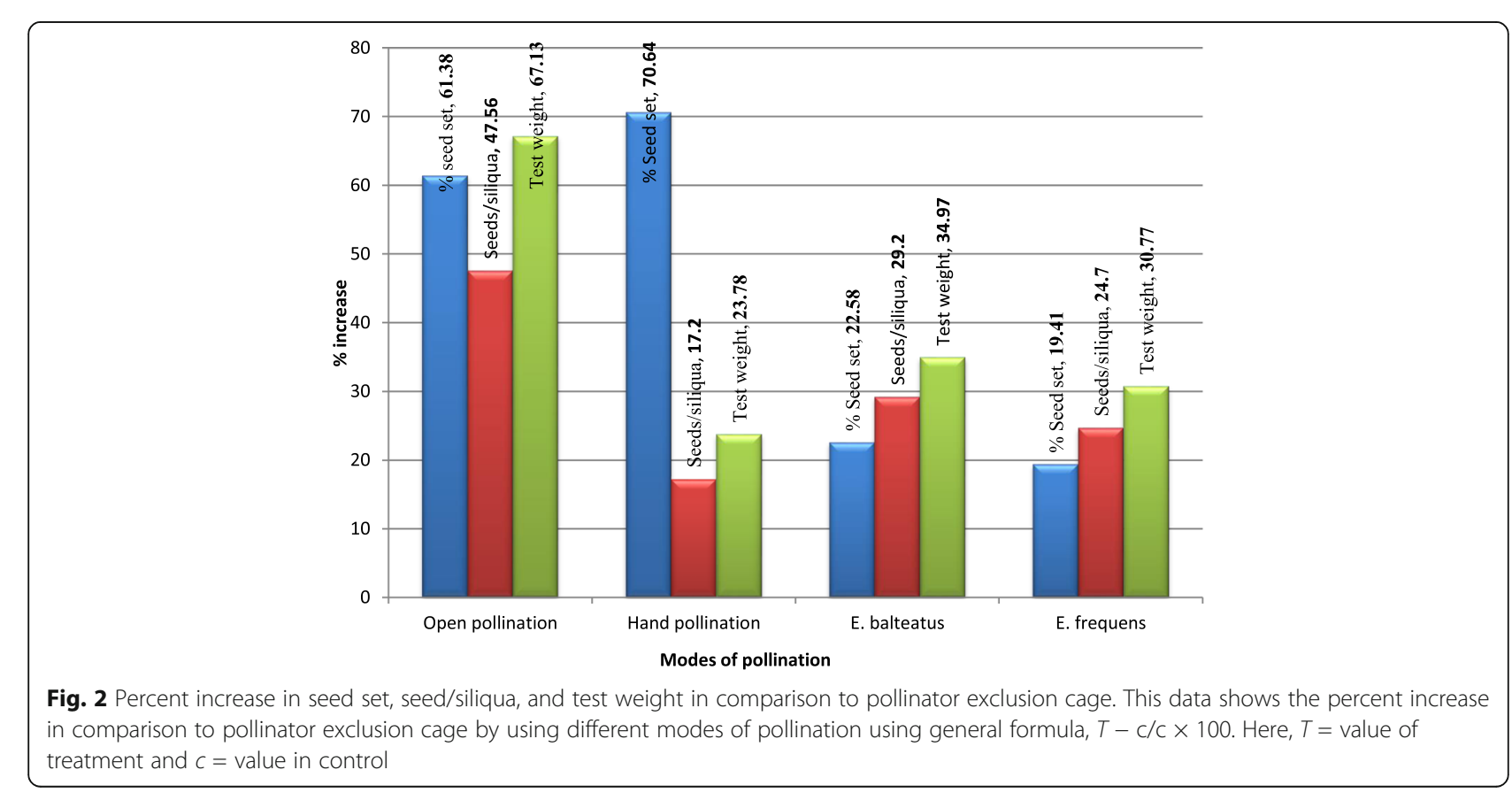


and 12.24 for pollinator exclusion cage, i.e., open pollination was better in agreement with present findings where open pollination plants produced maximum of 19.05 seeds per pod. Number of seeds/siliqua in B. juncea was high in open pollination (15.54 seeds per siliqua) which was at par with hand pollination 14.18 followed by pollinator exclusion cage (12.145 seeds per siliqua) (Devi et al. (2017). Present findings also found support from those of Pudasaini and Thapa (2014) who reported that high number of pods per plant (69.59) were observed from hand-pollinated plants than that in open pollination (64.96 pods per plant). In the present study, introduction of $E$. balteatus and $E$. frequens to cage resulted in $16.68 \%$ and $16.10 \%$ increase in number of seeds per siliqua (Fig. 2), whereas,E. balteatus and E. frequens resulted in yield increase of 112.4 and $96.3 \%$, respectively of strawberry over control (Hodgkiss et al. 2018).

In the present study, the weight of 1000 seeds of $B$. juncea varied from $1.43 \mathrm{~g}$ (control) to $2.3 \mathrm{~g}$ (open pollination). The syrphid species had less seed weight (1.87 to $1.93 \mathrm{~g}$ ) but higher than control. Statistically, higher weight of 1000 seeds $(3.12 \mathrm{~g})$ in open pollination than hand pollination $(2.98 \mathrm{~g})$ was reported for same crop $B$. juncea under similar conditions (Devi et al. 2017). Similar observations were recorded by Kumari et al. (2013) who observed a maximum seed weight of $4.6 \mathrm{~g} \mathrm{~B}$. juncea (cv. RLC-1) in open pollinated plots which was significantly higher than that in A. mellifera pollinated plots $(4.0 \mathrm{~g})$ and significantly lowest weight in pollination exclusion (3.8 g). Bhowmik et al. (2014) reported significant increase in mean weight of 100 seeds in open pollinated plants of B. juncea by $240 \%$ than the controlled plants where insect pollinators were excluded.

Less impact of aphidophagous hover flies as pollinators than bees has been reported by Garratt et al. (2016). In the present study, maximum number of seeds per siliqua and 1000 seed weight was observed in open pollinated plants which are exposed to the all type of insect pollinators. Previous research demonstrated that the high pollinator diversity pollinates various crops more effectively (Blitzer et al. 2016).

\section{Conclusion}

Total mean development period of E. frequens and $E$. balteatus was observed as 27.8 days and 26.3 days, respectively. Among the different larva instars of syrphids, 3rd instar larva plays an important role in aphid consumption by consuming maximum number of individuals of cabbage aphid. The daily aphid consumption by larva gradually increased after emergence from the egg and reached to the maximum at third instar and decreased just before pupation. The results of investigation on longevity and fecundity on different diets revealed that feeding of adult syrphids at $10 \%$ honey solution and fresh pollen grains prolonged the adult longevity and egg laying capacity per female and that diet was best suited for in vitro syrphid rearing. Syrphids also play an important role as pollinator on mustard and improve the seed production.

\section{Abbreviations \\ $<$ : Less than; >: Greater than; CD: Critical difference; Df: Degree of freedom; et al.: et alia (co-workers); i.e.: Id est (that is); No.: Number; NS: Non- significance; sp.: Species; SE: Standard error; viz:: Namely}

\section{Acknowledgements}

Authors are thankful to Head, Department of Entomology for providing facility to conduct present experiment Department of Entomology, Dr Y.S. Parmar University of Horticulture and Forestry.

\section{Authors' contributions}

Paramveer Singh carried out the experiments, recorded the data, interpreted the results, and wrote the manuscript. All the rest of the co-authors designed and supervised the experiments, provided technical guidance, and edited the manuscript. All authors read and approved the final manuscript during the present study.

\section{Funding}

Not applicable

Availability of data and materials

Not applicable

Ethics approval and consent to participate

Not applicable

\section{Consent for publication}

Not applicable

\section{Competing interests}

NA

Received: 30 April 2020 Accepted: 17 July 2020

Published online: 11 August 2020

\section{References}

Awadallah KT, Mahmoud TT, Khalil FM (1980) Egg-laying activities of the syrphid females, Metasyrphus corollae Fabr. and Sphaerophoria scripta L.(SyrphidaeDiptera). Mesopotamia J Agric 15:263-271

Bhowmik B, Mitra B, Bhadra K (2014) Diversity of insect pollinators and their effect on the crop yield on Brassica juncea L., NPJ-93, From Southern West Bengal. Int J Curr Sci 5:1207-1213

Blitzer EJ, Gibbs J, Park MG, Danforth BN (2016) Pollination services for apple are dependent on diverse wild bee communities. Agric Ecosyst Environ 221(1):-7

Devi M, Sharma HK, Thakur RK, Bhardwaj SK, Rana K, Thakur M, Ram B (2017) Diversity of insect pollinators in reference to seed set of mustard (Brassica juncea L.). Inter J Current Microb Appl Sci 6:2131-2144

Garratt MPD, Breeze TD, Boreux V, Fountain MT, McKerchar M, Webber SM, Coston DJ, Jenner N, Dean R, Westbury DB, Biesmeijer JC, Potts SG (2016) Apple pollination: demand depends on variety and supply depends on pollinator identity. PLoS One 11:e0153889

Goswami V, Khan MS (2014) Impact of honey bee pollination on pod set of mustard (Brassica juncea L.: Cruciferae) at Pantnagar. Bioscane 9:75-78

Hodgkiss D, Brown MJF, Fountain MT (2018) Syrphine hoverflies are efficient pollinators of commercial strawberry. J Pollination Ecol 22:55-66

Hong BM, Hung HQ (2010) Effect of temperature and diet on the life cycle and predatory capacity of Episyrphus balteatus (de Geer) (syrphidae: diptera) cultured on Aphis gossypii (glover). J Int Soc Southeast Asian Agric Sci 6:98-103

Hopper JV, Nelson EH, Daane KM, Mills (2011) Growth, development and consumpion by four syrphids species associated with the lettuce aphid. J Biol Control 58:271-276.

Iwai H, Niijima K, Matsuka M (2007) An artificial diet for aphidophagous syrphids, Episyrphus balteatus (de Geer) and Eupeodes bucculatus (Rondani) (Diptera: 
Syrphidae) using drone honeybee brood powder. Appl Entomol Zool 42: $167-172$

Jalilian F (2015a) Development and feeding capacity of Scaeva albomaculata (Macqaurt) (Diptera: Syrphidae) fed with rose aphid, Macrosiphum rosae (Homoptera: Aphididae). Biological Forum 7:1377

Jalilian F (2015b) Biology and larval feeding rate of Episyrphus balteatus (Diptera: Syrphidae) on Aphis pomi (Hom.Aphididae) at laboratory conditions. Biological Forum 7:1395

Jalilian F, Karimpour Y, Aramideh S, Gilasian E (2016) Investigation on some biological characteristics of Eupeodes corollae (Dip.: Syrphidae) on Aphis pomi (Hom: Aphididae) in vitro. J Entomol Zool Studies 4:432-435

Jauker F, Wolters V (2008) Hover flies are efficient pollinators of oilseed rape. Oecologia 156:819-823

Khan IA, Ahmad M, Akbar R, Hussain S, Saeed M, Farid A, Shah AR, Fayaz W, Shah B, Din MMU (2015) Study on aphids density and yield components of 12 brassica genotypes under field conditions in Peshawar, Pakistan. J Entomol Zool Stud 3:11-15

Kumari S, Chhuneja PK, Singh J (2013) Seed yield augmentation by insect pollinators in Brassica juncea. In: Abstracts of 4th International Congress on Insect Science, University of Agriculture Science, Banglore, Karnatka, $14^{\text {th }}$ to $17^{\text {th }}$ February 2013

Manpoong NS, Firake DM, Behere GT, Rajesh T (2016) Biological attributes and feeding potential of three dominant predators of Lipaphis erysimi (Kaltenbach). J Biol Control 30:190-194

Morandin LA, Winston ML (2006) Pollinators provide economic incentive to preserve natural land in agro ecosystems. Agric Ecosyst Environ 116:289-292

Nagpal K, Yadav S, Kumar Y, Singh R (2017) Effect of pollination modes on yield components in Indian mustard (Brassica juncce L.). J Oilseed Brassica 8:187-194

Pudasaini R, Thapa RB (2014) Effects of pollination on rapeseed ( Brassica campestris L.Var. Toria) production in Chitwan (Nepal). J Agric Environ 15:41-45

Rathore SS, Shekhawat K, Meena PD, Singh VK (2018) Climate smart strategies for sustainable production of rapeseed-mustard in India. J Oilseed Brassica 9:1-9

Roy S, Gayen AK, Mitra B, Gupta DA (2014) Diversity, foraging activities of the insect visitors of mustard (Brassica juncea $\mathrm{L}$ ) ) and their role in pollination in West Bengal. J Zool Stud 1:7-12

Sadeghi H (2008) Abundance of adult hoverflies (Diptera: Syrphidae) on different flowering plants. Caspian J Environ Sci 6:47-51

Sadeghi H, Gilbert F (2000) Aphid suitability and its relationship to oviposition preference in predatory hoverfly. J Anim Ecol 69:771-784

Singh K, Singh NN (2013) Preying capacity of different established predators of the aphid Lipaphis erysimi (Kalt.) infesting rapeseed-mustard crop in laboratory conditions. PInt protect sci 2:84-88

Sutherland JP, Sullibvan MS, Poppy GM (1999) The influence of floral characters on the foraging behavior of the hoverfly, Episyrphus balteatus. Ent Exp et Appl 93:157-164

Vance NC, Bernhardt P, Edens RM (2004) Pollination and seed production in Xerophyllum tenax (Melanthiaceae) in the Cascade range of Central Oregon. American J Bot 91:2060-2068

Verma JS, Sharma KC, Sood A, Sood M (2005) Biology and predatory potential of syrphid predators on Aphis fabae infesting Solanum nugrum (L.). J Entomol Res 29:39-41

\section{Publisher's Note}

Springer Nature remains neutral with regard to jurisdictional claims in published maps and institutional affiliations.

\section{Submit your manuscript to a SpringerOpen ${ }^{\circ}$ journal and benefit from:}

- Convenient online submission

- Rigorous peer review

- Open access: articles freely available online

- High visibility within the field

- Retaining the copyright to your article

Submit your next manuscript at $\boldsymbol{\nabla}$ springeropen.com 